\title{
- Lúpus eritematoso discóide - LED: Revisão e casuística em serviço especializado da Capital de São Paulo
}

\section{- Discoid lupus erythematosus: General review and a series of cases of a specialized service in the city of São Paulo, Brazil}

\author{
* Faculdade de Medicina \\ Veterinária e Zootecnia - USP \\ Departamento de Clínica Médica \\ Serviço de Dermatologia \\ Av. Prof. Dr. Orlando Marques de \\ Paiva, 87 \\ Cidade Universitária \\ São Paulo - SP \\ e-mail: borges@usp.br
}

\author{
* Carlos Eduardo Larsson ${ }^{1}$-CRMV-SP n ${ }^{0} 1037$ \\ Mary Otsuka ${ }^{2}$ - CRMV-SP n ${ }^{\circ} 8503$ \\ ${ }^{1}$ Professor Titular do Departamento de Clínica Médica - FMVZ - USP \\ ${ }^{2}$ Médica Veterinária do Serviço de Dermatologia do Hospital Veterinário - FMVZ - USP
}

\section{RESUMO}

Em função de sua grande ocorrência em serviço especializado de dermatologia, vinculado ao Hospital Veterinário da Universidade de São Paulo, revisam-se os principais aspectos do lúpus eritematoso discóide, no que se refere às suas etiopatogenia, epidemiologia, aos aspectos sintomáticos e lesionais (em carnívoros e herbívoros domésticos), diagnóstico e protocolo de terapia. Enfocam-se dados brasileiros (paulistas e cariocas) e norte-americanos, relativos à magnitude de ocorrência frente às demais doenças auto-imunes diagnosticadas, segundo as variáveis: definição racial, sexual e idade de carnívoros domésticos, comparando-os àqueles evidenciados em pacientes humanos.

Palavras chave: LE cutâneo, LE discóide, LE fixo, “Collie nose”, lúpus eritematoso.

\section{Etiopatogenia}

o homem, o lúpus eritematoso discóide (LED) e o lúpus eritematoso sistêmico (LES) podem ser considerados como formas clínicas polares de uma mesma enfermidade ou como entidades clínicas individualizadas. A transição da forma fixa (LED) para a forma sistêmica não ocorre (MARTEN e BLACKBURN, 1961) ou é muito pouco freqüente, aparecendo em percentis oscilantes entre menos de $5 \%$ (SAMPAIO et al., 1982) à, no máximo, 6,5\% de conversões (MILLARD e ROWELL, 1979). Em medicina veterinária não se tem evidenciado a conversão da forma fixa para a sistêmica, nos cães e, tampouco, nos eqüinos acometidos (SCOTT, 1988; SCOTT et al., 1996).

Contrariamente ao que está bem caracterizado nos quadros de LES (Tabela 1), que cursam com lesões cutâneas, por vezes múltiplas, mormente em áreas expostas, com comprometimento visceral, com intensidade e evolução variáveis (aguda, subaguda ou crônica) e, esporadicamente, até fatal, o LED é dermatose relativamente benigna, principalmente por inexistirem manifestações sistêmicas, o que lhe confere, habitualmente, bom prognóstico e o entendimento de que se constitua em variante benigna da enfermidade lúpica, tanto em medicina humana como na medicina veterinária. 
Tabela 1 - Freqüências das manifestações clínicas do LES em cães e no homem.

\begin{tabular}{|l|c|c|}
\hline Manifestação & Cão & Homem \\
\hline Febre & 100 & $55-86$ \\
Poliartrite & 90,6 & $89-100$ \\
Nefropatia & 65.3 & $40-60$ \\
Dermatopatia & 60 & $25-70$ \\
Linfoade/esplenomegalia & 49.3 & $20-67$ \\
Anemia hemolítica & 13.3 & 12.4 \\
Trombocitopenia & 4 & $8-50$ \\
Miosites & 8 & - \\
Pleuropericardite & 8 & $25-56$ \\
Neuropatias & 1.6 & 40 \\
Polineurites & 1.3 & $2.5-20$ \\
\hline
\end{tabular}

Fonte: CHABANNE et al., (1999).

A etiopatogenia é, ainda, basicamente desconhecida na medicina, seja humana, seja veterinária. Difere, em termos gerais, de uma aparente etiologia multifatorial, relatada nos animais e no homem, acometidos pelo LES.

No LES considera-se haver uma origem genética, predispondo tanto pacientes humanos como caninos a desenvolver esta modalidade. De fato, existe determinado percentil de incidência da doença e de anomalias sorológicas em ascendentes de famílias de pacientes, humanos e caninos, com LES. Segundo PROENÇA et al., (1989), na Faculdade de Ciências Médicas da Santa Casa de Misericórdia de São Paulo (FCMSCM), no período de 1982-1988, pôde-se identificar 4\% de pacientes acometidos por LES, que possuíam uma história familiar do quadro clínico. Em veterinária, em linhagens de cães Berger Alemães, considera-se que a presença de haptotipos (antígeno DLA-77) teriam um valor preditivo da enfermidade (OLIVRY, 1996).
Também, na etiopatogenia do LES canino, aventou-se o papel desempenhado por retrovírus, pelos vírus vacinais da cinomose, da hepatite, da para-influenza e do parvovírus; em cães e camundongos, pelos hormônios estrogênicos com incidência maior em fêmeas e uma aparente proteção conferida pelos andrógenos e pelas drogas antiestrogênicas utilizadas em modelos experimentais com murinos, por fatores ambientais (alimentos e radiação actínica) e por drogas, no homem (procainamída, hidralazina, isoniazida, penicilamina, anticonvulsivantes e anticonceptivos) e, nos outros animais, por imunógenos.

De todo esse mecanismo multifatorial, descrito para o LES, apenas a radiação ultravioleta é considerada como um fator desencadeante ou perpetuante do LED em cães, em eqüinos e no próprio homem (SAMPAIO et al., 1982; OLIVRY, 1996; SCOTT et al., 1996). Cerca de $50 \%$ de cães com LED manifestam agravamento do quadro frente à exposição solar cotidiana (SCOTT et al., 1996).

No LE canino, a patogenia das lesões de pele é ainda incerta. Têm-se como características da apresentação das lesões tegumentares: a fotossensibilidade (tanto ao UVA como ao UVB), a lesão de ceratinócitos (associados a linfócitos T e a macrófagos), a infiltração linfocitária (no homem há predomínio de plasmócitos, todavia, consideramse os linfócitos b como importantes), a produção de autoanticorpos e a deposição de imunocomplexos.

Na Figura 1, dispõe-se, de forma esquemática, o suposto mecanismo etiopatogênico responsável pelo de-

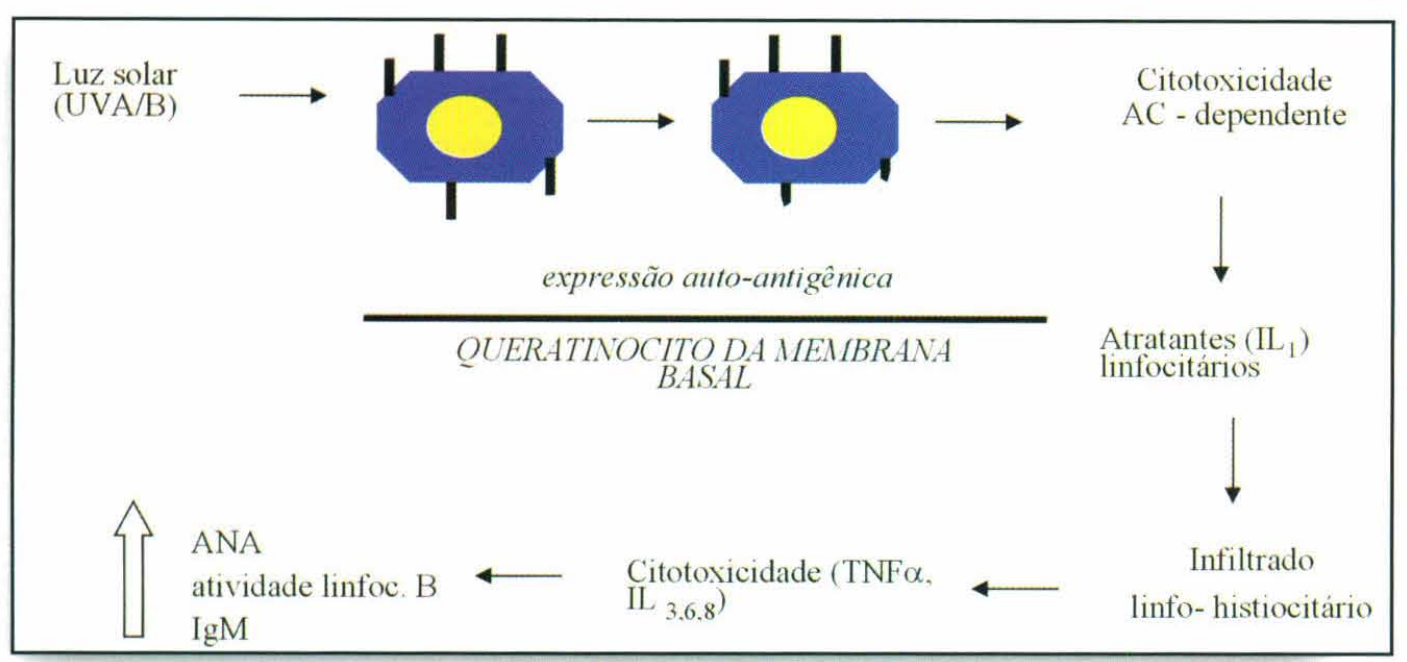

Figura 1: Esquema da etiopatogenia do LED canino sencadeamento dos quadros de LED, qual seja: a indução, pela radiação ultravioleta (UVA e UVB), da expressão de auto-antígenos (citoplasmáticos e nucleares), na superfície da membrana celular dos ceratinóticos. Subseqüentemente, há a produção de auto-anticorpos que se ligam aos antígenos superficiais dos ceratinócitos, ao nível da membrana basal, 
desencadeando fenômenos citotóxicos. Os ceratinócitos lesados liberam interleucinas $\left(\mathrm{IL}_{1}, \mathrm{IL}_{3}, \mathrm{IL}_{6}, \mathrm{IL}_{8}\right)$, fatores alfa de necrose tumoral, estimuladores e ativadores de granulócitos, monócitos e macrófagos. A essas alterações se associam, nos casos de LES com manifestações cutâneas $(50 \%$ e $33 \%$ dos casos de LES, em cães e gatos respectivamente, segundo KIMM e NOXON, 1985) e elevação da produção de imunoglobulinas, da atividade de linfócitos b e dos níveis de anticorpos anti-nucleares (ANA).

No que tange ao LE, mormente na variedade sistêmica, sugere-se o envolvimento de um mecanismo de hipersensibilidade do tipo III, ou seja, deposição de imunocomplexos.

\section{Caracterização epidemiológica comparada ao LED}

No LES humano, a ocorrência, em termos de predisposição sexual, é na proporção de 8 mulheres: 1 homem, segundo SAMPAIO et al., (1982) e de 3 mulheres: 1 homem, segundo PROENÇA et al., (1989).

O LED acomete pacientes em média de idade de 36,8 anos (PROENÇA et al., 1989) sendo muito mais freqüente em pacientes brancos $(68 \%)$ relativamente aos pardos, negros ou amarelos. Em São Paulo, na FCMSCM, no período de 6 anos (19821988 ), atendia-se um caso de LED a cada 361 novas consultas.

O LED foi descrito em caninos na década de 70 (ROSEKRANTZ, 1993), nos eqüinos e em felinos (WILLIAMS et al., 1989; GUAGUERE e MAGNOL, 1989) na década de 80. No Brasil, a primeira citação de LED em cão data de 1985 (LARSSON et al., 1985). Inexistem relatos de ocorrências, no país, do LED em outros espécimens de animais, domésticos ou selvagens.

O LED é considerado, nos Estados Unidos, como a segunda dermatose auto-imune dentre os cães, ficando aquém apenas dos casos de pênfigo foliáceo. A modalidade fixa do LE canino representa, no Hospital Veterinário do New York State College of Veterinary
Tabela 2 - Dados comparativo da apresentação de LED em cães, segundo a definição racial (\%), em São Paulo e Nova Iorque.

\begin{tabular}{|l|c|c|}
\hline & $\begin{array}{c}\text { Brasil } \\
\text { (São Paulo) }\end{array}$ & $\begin{array}{c}\text { EUA } \\
\text { (Nova lorque) }\end{array}$ \\
\hline Akita & 43,7 & - \\
Pastor Alemão & 18,7 & $18,8(7,6)$ \\
Pinscher & 12,5 & - \\
Collie & - & $37,5(4,5)$ \\
Pastor de Shetland & - & $12,5(1,0)$ \\
Husky Siberiano & - & $12,5(1,3)$ \\
\hline ( ) - \% de demanda relativa à raça na população do Hospital do New \\
York State College of Veterinary Medicine (EUA). \\
\hline
\end{tabular}

Fonte: SCOTT et al., (1987), LARSSON (1998).

Medicine, cerca de $0,3 \%$ de todas as dermatoses. O LES, por sua vez, teria um percentual de ocorrência de $0,03 \%$ (SCOTT et al., 1983a, 1987) (Tabela 2).

Em São Paulo, no Serviço de Dermatologia da Faculdade de Medicina Veterinária e Zootecnia da Universidade de São Paulo (LARSSON et al., 1998), no período de 1986-1998, dentre os 68 casos de dermatoses auto-imunes diagnosticados, 35 eram de doença lúpica $(51,5 \%)$, sendo $31(45,5 \%)$ da modalidade fixa (Figura 2). No Rio de Janeiro, por sua vez, no período de 1993 1997, no Serviço de Dermatologia da Universidade Federal Rural do Rio de Janeiro, diagnosticaram-se 28 casos de dermatoses auto-imunes, sendo 17 casos de LE $(60,7 \%)$. Destes, apenas dois $(7 \%)$ eram de LED; os demais $15(53,5 \%)$, eram da forma sistêmica (RAMADINHA et al., 1993).

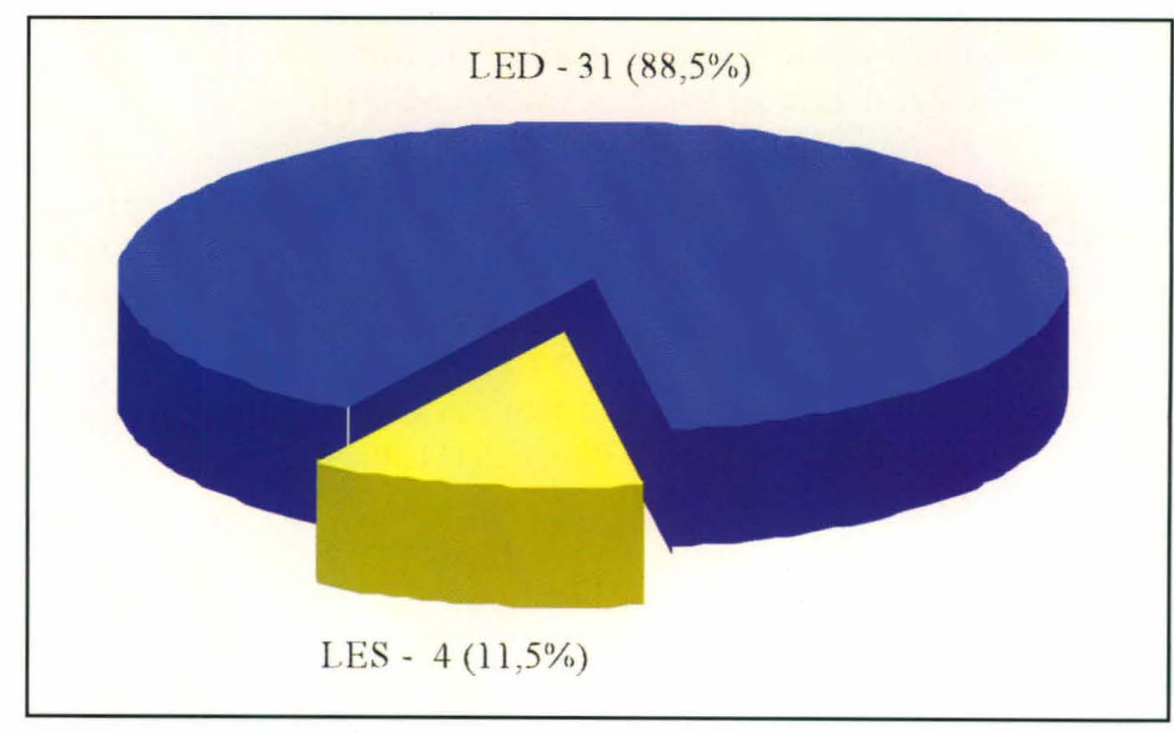

Figura 2: Prevalência do lúpus eritematoso em caninos. Serviço de Dermatologia da FMVZ/ USP, 1986-1998 


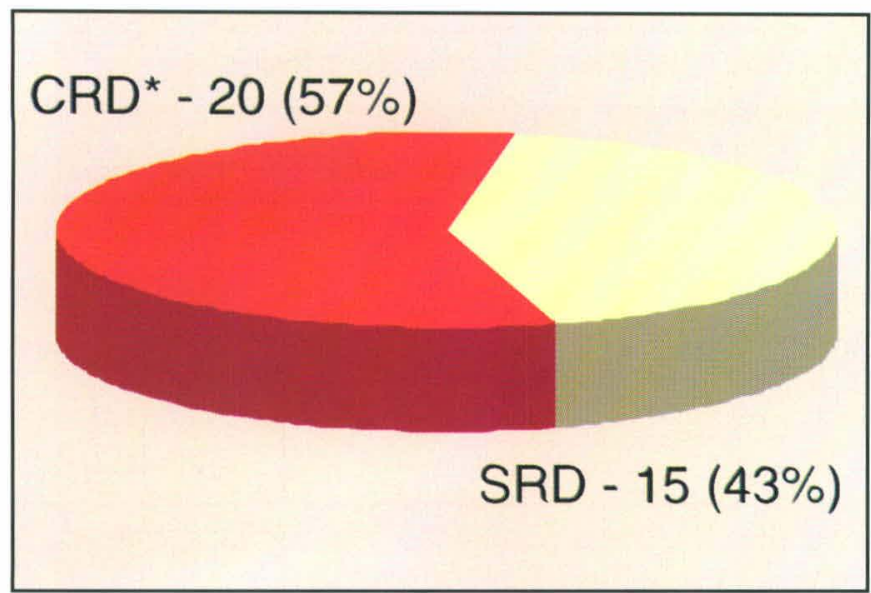

Figura 3: Prevalência de LED em cães, segundo a definição racial e raça. Serviço de Dermatologia da FMVZ/USP, 1986-1998

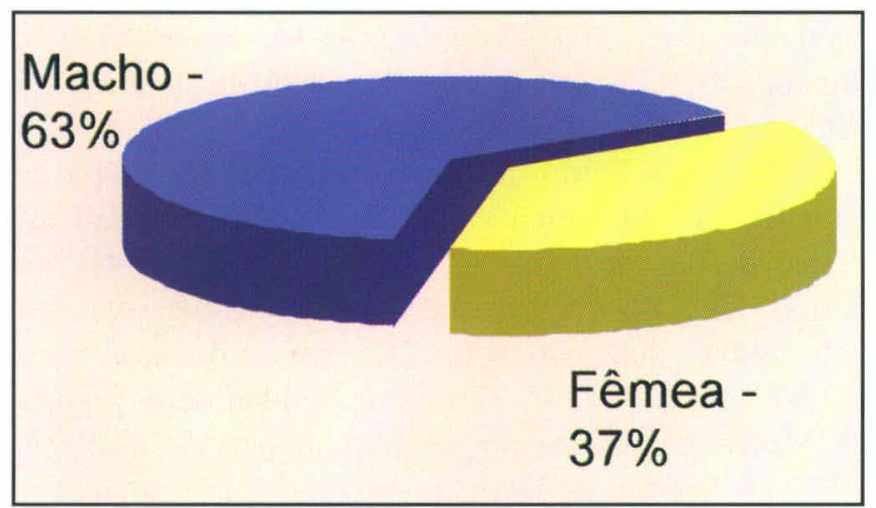

Figura 4: Prevalência de LED em cães, segundo o sexo. Serviço de Dermatologia da FMVZ/USP, 1986-1998

Aparentemente, nos cães acometidos pelo LED, em São Paulo (Figuras 3 e 4), inexiste predisposição relativa à definição racial $(57,0 \%$ em animais com raça definida, sendo, todavia, mais freqüente em animais entre o segundo e quinto ano de vida (68\%) e, curiosamente, dentre os machos (63\%). SCOTT et al., (1996), nos EUA, e CARLOTTI (1989), na França, afirmaram inexistir predisposição sexual ou etária.

No que tange aos animais de raça definida (Figura 3), aqueles mais acometidos no Brasil (São Paulo) são Akita $(43,7 \%)$, Pastor Alemão $(18,7 \%)$ e Pinscher $(12,5 \%)$. Nos EUA (SCOTT et al., 1996) são Collies $(37,5 \%)$, Pastor Alemão (18,8\%), Pastor de Shetland $(12,5 \%)$, Husky Siberiano (12,5\%).

\section{Quadros sintomáticos e lesionais}

\section{Eqüinos}

Topograficamente, as lesões instalam-se nas regiões cefálica (face e pavilhões auriculares) e cervical, sob a forma de máculas alopécicas, eritematosas, descamativas, crostosas, com evolução para discromia tegumentar e pilar (leucodermia e leucotriquia) (SCOTT, 1988).

\section{Felinos}

Também, apresentam lesões (alopecia, eritema, escamas e crostas), predominantemente, faciais e auriculares, com igual tendência àquela dos eqüinos, para a despigmentação tegumentar nasal (KIMM e NOXON, 1985).

\section{- Caninos}

Inicia-se o quadro pela discromia progressiva do plano nasal (de negro transforma-se numa coloração acinzentada ou azul escura) com concomitante substancial modificação na arquitetura desta região (de aspecto losângico e áspero, dito em "calçamento de pedra", torna-se liso), aspecto este que auxilia na diferenciação diagnóstica com o vitiligo, uma vez que superpõem-se eritema e descamação nasal. Em fases tardias, surgem lesões erodo-ulcerativas e crostosas. A dermatite nasal, vista em 95,4\% dos casos, com certa freqüência tem o aspecto típico em "asa de borboleta" ou em "vespertílio", tal como o evidenciado em pacientes humanos. Estas lesões nasais são vistas, inicialmente, na porção dorsal, na junção muco-cutânea ou ao longo das porções ventral ou medial, das dobras alares, tendendo a evoluir para toda região nasal incluindo a ponte (Figuras 5 a 9).

Menos freqüentemente se têm lesões auriculares $(25 \%)$, perioculares $(19 \%)$, labiais $(12,5 \%)$, palatinas $(12,5 \%)$, distais dos membros $(12,5 \%)$, sob a forma de pododermatite generalizada (OLIVRY, 1996), e na genitália. Por vezes, há lesões estritamente nasodigitais $(6,2 \%)$ ou auriculares (SCOTT et al., 1983).

A dor e o prurido são de intensidade variável, no geral de pouca importância (OLIVRY, 1996). O prurido relatado por 10,5\% daqueles pacientes humanos (PROENÇA et al., 1989), é de intensidade variável, e igual, segundo o decurso evolutivo, nos animais acometidos.

A tendência evolutiva é a formação de cicatrizes e de leucodermia, de intensidade variável. Quando ocorre agravamento lesional nasal, com formação de úlceras atingindo arteríolas, embora raro, pode ocorrer quadro hemorrágico agudo.

\section{Diagnóstico}

Baseia-se, para sua elaboração, nos dados anamnésicos, nos achados do exame físico e nos resultados da 


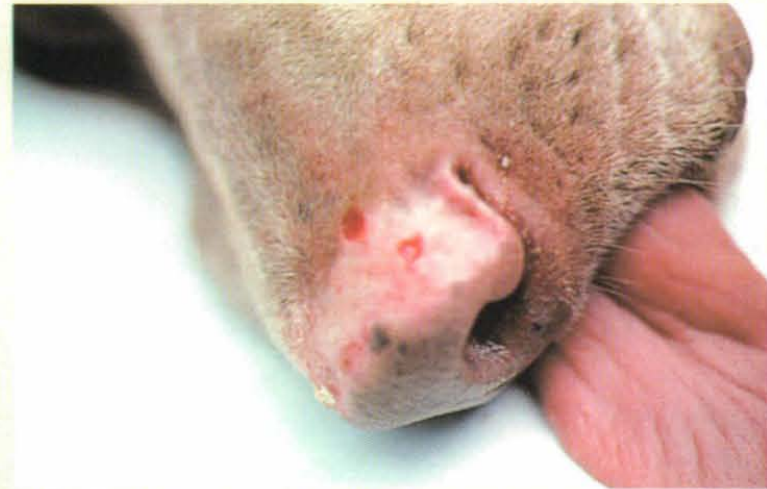

Figura 5: Weimaraner com LED - plano nasal discrômico, com perda do sulcamento típico. Lesões, vestigiais, decorrentes da biópsia com "punch" de Keye (CEL/93).

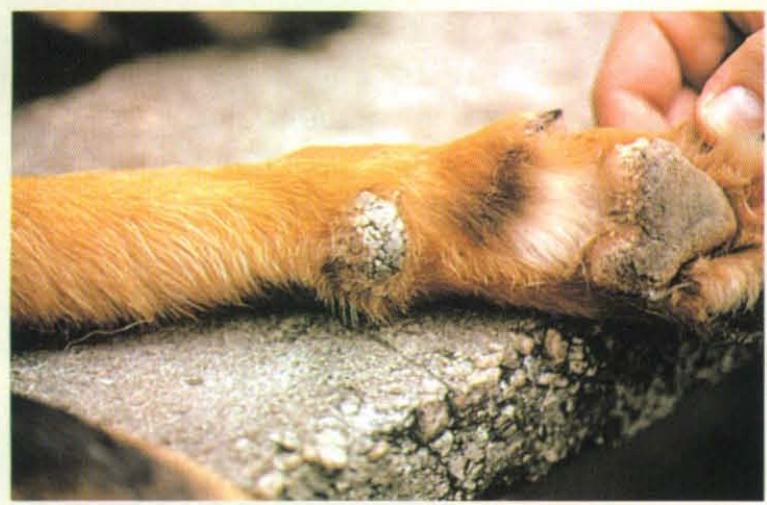

Figura 6: Pastor Alemão com LED - coxins plantares ceratóticos mimetizando lesões vestigiais de cinomose ou aquelas do pênfigo foliáceo (CEL/97).

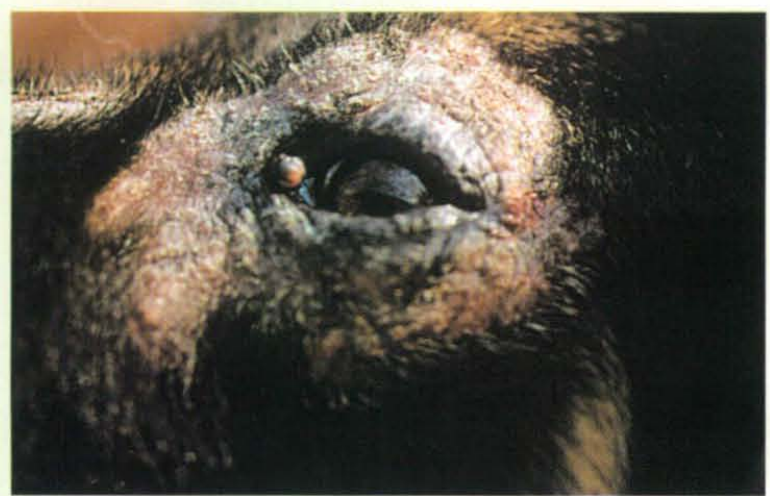

Figura 7: SRD - lesão geográfica periocular, alopécica, ceratótica, crostosa, erosada, com eritema de base, mimetizando quadros de demodicidose, hipovitaminose $\mathrm{H}$ ou síndrome úveo-dermatológico. (CEL/95).

histopatologia da pele. Habitualmente, não se interpõem maiores dificuldades para estabelecê-lo, contrariamente ao que é habitual nos casos de LES que, segundo SCOTT et al., (1996), é um dos maiores desafios ao clínico, face à pletora de manifestações em distintos órgãos ou sistemas.

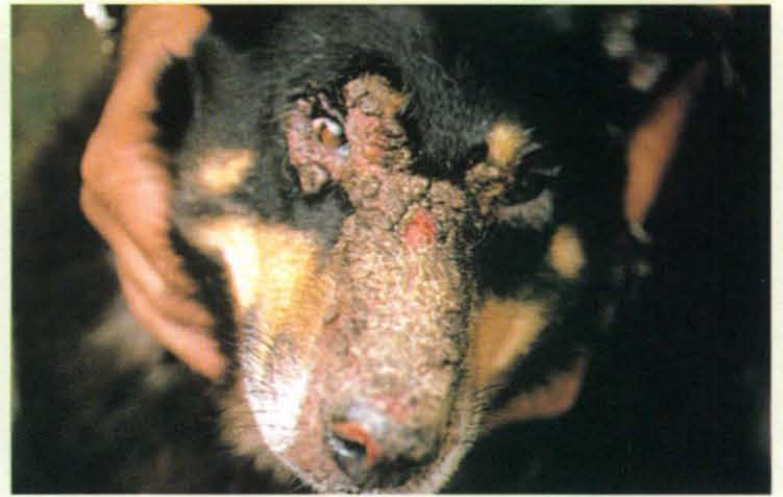

Figura 8: SRD - lesão facial, em vespertílio, alopécica, ceratótica e erosada. Erosão no espelho nasal. Mimetiza aquelas de penfigo eritematoso, dermatite actínica ou demodicidose. (CEL/97).

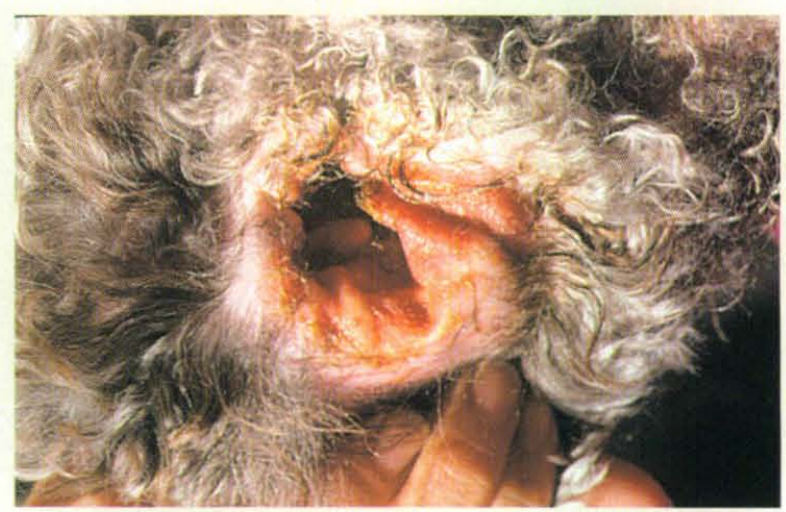

Figura 9: Poodle com LED - pavilhão auricular (face medial) com notável eritema, áreas erosadas, exsudativas e com deposição de material melicérico (CEL/95).

Os resultados de determinação do quadro hemático, do exame de urina e da bioquímica sérica (eletroforese de proteínas séricas) são irrelevantes para efeito de estabelecimento do diagnóstico. A pesquisa da eventual presença de células LE é quase sempre negativa. Os testes sorológicos, em busca de anticorpos antinucleares, raramente mostram resultados positivos e, quando o são, segundo SCOTT et al., (1983, 1983a), em seis porcento dos casos, os títulos são muito baixos. Segundo WHITE et al., (1992), em apenas 9,4\% dos cães, com LED respectivamente, vê-se a presença de antígenos nucleares extraíveis e de antígeno protéico ribonuclear.

Já o exame histopatológico de pele biopsiada propicia elementos fundamentais para a conclusão diagnóstica. Observam-se, habitualmente, dermatite de interface (dos tipos liquenóides, hidrópica ou de ambas), marcante degeneração hidrópica (81\%), presença (94\%) de ceratinócitos apoptóticos (células basais degeneradas, arredondadas, eosinofílicas, bem individualizadas - "corpos colóides" ou de "civatte"), incontinência pigmentar 
$(87,5 \%)$, infiltrado de células mononucleares e de plasmócitos (perivasculares e peri-apendiculares), depósito dérmico exagerado de mucopolissacarídeos (ácido hialurônico) (SCOTT et al., 1983, 1983a, 1996; OLIVRY, 1996).

Na imunopatologia, através da imunofluorescência direta (IFD) evidenciam-se deposição de imunoglobulinas (IgA - 70\%; IgG - 40\%; IgM - 40\%) e/ou de complemento $\left(\mathrm{C}_{3}-90 \%\right)$ ao longo da membrana basal, de aspectos linear a granuloso, regular ou irregular. Há que se ter extremo cuidado ao se interpretar a positividade quanto à presença de IgM ao longo da membrana nasal dos coxins e focinho de cães e gatos, já que este achado é habitual (SCOTT et al., 1982, 1983, 1983a, 1996; GROSS et al., 1992; OLIVRY, 1996). Deve-se colher fragmentos de pele, para a IFD, de áreas despigmentadas, eritematosas e não ulceradas, recorrendo-se, quando possível, ao fixador de Michel, que preserva as deposições por longo período. Portanto, o chamado teste de banda lúpica é positivo na quase totalidade dos animais com LED, tendo sido detectado, também, na parede de vasos dérmicos (10\% dos casos) tal como no homem (HALLIWELL, 1981; SCOTT et al., 1983, 1983a; ROSEKRANTZ, 1993.).

Os resultados dos testes de imunofluorescência indireta (IFI) são sempre negativos. Como alternativa à IFD, para a detecção de imunoreatores, tem-se o teste da imunoperoxidase (IP) que apresenta, como vantagem, a possibilidade de empregar fragmentos de tegumento fixados e já preparados. Ainda mais, não necessita do custoso equipamento de IF. Todavia, a grande desvantagem da IP decorre do grande número de resultados falso-positivos (MOORE et al., 1987).

Considera-se, entretanto, que os testes imunopatológicos são desnecessários para a elaboração do diagnóstico conclusivo e devem, portanto, ficar num segundo plano, frente à corriqueira histopatologia, sendo, então, nada mais que uma mera complementação.

\section{Diagnóstico diferencial}

Com dermatoses, mormente aquelas com sede no plano e espelho nasal:

LES, complexo pênfigo (foliáceo ou eritematoso), farmacodermias (eritema polimorfo), micose fungóide, síndrome de Vogt-Koyanagi-Harada "simile", dermatite de contacto, carcinoma espinocelular, "collie-nose", dermatomiosite familiar canina, demodiciose, dermatofitose, piodermites, dermatoses actínicas, ceratose naso-digital e vitiligo.

\section{Terapia}

Face ao curso, habitualmente, benigno do quadro de lúpus fixo, os protocolos de terapia, a escolher, não causam grandes dúvidas ao clínico. Embasam-se na gravidade do quadro e na opção do proprietário. Recomenda-se, sempre, a educação e orientação dos proprietários, para que se evite a exposição solar, e que se use fotoprotetores (FP15). Geralmente, recorre-se à corticoideterapia tópica e à vitaminoterapia (vitamina E). Nos casos refratários a estas medidas, aí sim, utilizam-se dos corticosteróides sistêmicos (ROSEKRANTZ, 1993) ou de combinações vitamino-antibióticas, "per-os".

À terapia com vitamina E (DL - acetato de alfa tocoferol, na dose de 400-800 UI por animal, a cada doze horas, duas horas antes ou após o repasto), habitualmente se associa a corticoideterapia.

Terapia tópica, com especialidades farmacêuticas, à base de corticóides fluorados, duas vezes ao dia (durante 10-14 dias) e, após a remissão do quadro agudo, aumentando-se o intervalo posológico (para cada 48 ou 72 horas) ou passando para aqueles menos potentes (hidrocortizona a $0,5-2,5 \%$ ).

A associação tetraciclina e niacinamida (nicotinamida) é uma alternativa de terapia bastante utilizada (WHITE, et al., 1990) com eficácia, no LED, de $14 \%$ ( bons resultados) e $65 \%$ (resultados excelentes). Destarte, alguns autores como ROSEKRANTZ (1993) somente obtiveram respostas, de qualquer magnitude, em apenas $25 \%$ dos casos. A dose recomendada é de $250 \mathrm{mg}$, de cada uma das drogas, para cães com menos de 10 quilogramas e o dobro desta para aqueles com mais de 10 quilogramas de peso, a cada 8 horas, "per-os". Como efeitos colaterais observam-se, raramente, vômitos, diarréia e anorexia. Nestes casos, deve-se retirar a niacinamida do protocolo.

$\mathrm{Na}$ corticoideterapia oral, emprega-se a prednisona $(1 \mathrm{mg} / \mathrm{kg}$, VO, cada 12 horas, durante cerca de 2 semanas) passando, quando da melhora, para o esquema de dias alternados. Em alguns casos somente se necessitam de corticóides sistêmicos ao menos nos meses estivais.

Raramente se emprega a azatioprina combinada aos corticóides (usam-se 1-1,5 mg/kg a cada 24 horas/VO e, com a melhora, a cada 48-72 horas). Monitorar o número de plaquetas e hemácias, a cada 2 semanas, durante os primeiros 3 ou 4 meses e, a seguir, a cada um ou dois meses. É, ainda, recomendável a determinação, também, da função hepática. 


\section{SUMMARY}

As a result of its occurrence in the dermatology service of the Veterinary Hospital of the Universidade de São Paulo, the main aspects related to etiopathogeny, epidemiology, symptoms and lesions (both in domestics carnivores and herbivores), diagnosis and treatment protocol of discoid lúpus erythematosus are reviewed in this study. Brazilian and American data are presented and discussed in relation to the occurrence of other auto-immune diseases according to variables such as race definition, sex and age of domestics carnivores, which are compared to those reported in humans.

Key words: Cutaneous lupus erythematosus, Collie nose, immunemediated dermatosis of dogs.

\section{REFERÊNCIAS BIBLIOGRÁFICAS}

1 - CARLOTti, D.N. Autoimmune mediated skin diseases. J. Small Animal Practice, v. 30, n. 4, p. 223-7, 1989.

2 - CHABANE, L.; FOURNEL, C.; RIGAL, D.; MONIER, J.C. Canine systemic lúpus erythematosus. Part II. Comp. Cont. Ed., v. 21, n. 5, p. 402-21, 1999.

3 - GROSS, T.L.; IHRKE, P.J.; WALDER, E.J. Veterinary dermatopathology. St. Louis: Mosby, 1992. p. 22-6.

4 - GUAGUÉRE, E.; MAGNOL, J.P. Lúpus érythémateux discoide à localisation auriculaire chez le chien. Prat. Méd. Chirur. Anim. Comp., v. 24, n. 2, p. 101, 1989.

5 - HALLIWELL, R.E.W. Skin diseases associated with autoimmunity. Part II. The nonbullous autoimmune skin diseases. Comp. Cont. Ed., v. 3, n. 1, p. 156-62, 1981.

6 - KIMM, T.J.; NOXON, J.O. Systemic lupus erythematosus in dogs and cats. Iowa State Veterinarian, v. 45, n. 2, p. 105-10, 1985.

7 - LARSSON, C.E.; ARAUJO, V.C.; GONÇALVES, M.A.; PARANHOS, A.S. Lúpus eritematoso discóide em cão, da Capital São Paulo. In: CONGRESSO BRASILEIRO DE CLÍNICOS VETERINÁRIOS DE PEQUENOS ANIMAIS, 8, Porto Alegre, Rio Grande do Sul, ANCLIVEPA-RS, 1985. Anais.

8 - LARSSON, C.E.; OTSUKA, M.; LUCAS, R.; NAHAS, C.R.; PENTEADO, A.L.B.; GONÇALVES, M.A.; MICHALANY, N.S.; BALDA, A.C. Immune mediated dermatosis in dogs of São Paulo - Brazil - Epidemiological aspects. In: CONGRESS OF THE WORLD SMALL ANIMAL VETERINARY ASSOCIATION, 23, - Buenos Aires: WSAVA-AVEACA, October 1998, Proceedings, Tomo II, p. 809.
9 - MARTEN, R.H.; BLACKBURN, E.K. Lúpus erythematosus: a 5-year follow-up of 77 cases. Arch. Dermatol. v. 83 , p. $430-6,1961$.

10 - MILLARD, L.G.; ROWELL, N.R. Abnormal laboratory test results and their relationship to prognosis in discoid lúpus erythematosus. Arch. Dermatol. v. 115, n. 9, p. 1055-8, 1979.

11 - MOORE, F.,M.; WHITE, S.D.; CARPENTER, J.L.; TORCHON, E. Localization of immunoglobulins and complement by the peroxidase antiperoxidase method in autoimmune and non autoimmune canine dermatopathies. Vet. Immuno/Immunopath., v. 14, n.1, p. 1-9, 1987.

12 - OLIVRY, T. Les dermatoses auto-immunes: 20 ans plus tard. In: JOURNÉE DE DERMATOLOGIE VÉTÉRINAIRE, $6^{\text {eme }}$, Bruxelles: SAVAB, 1996. Proceedings.

13 - PROENÇA, N.G.; FRUCCHI, H.; BERNARDES, M.F. Aspectos epidemiológicos do lúpus eritematosos discóide em São Paulo - Brasil. An. bras. Dermatol., v. 64, n. 3, p. 159-60, 1989.

14 - RAMADINHA, R.R.; TORRES, L.F.; GONZÁLEZ, A.P.; LATORRE, O.J.M. a survey of canine autoimune skin diseases seen in the Small Animal Veterinary Hospital, UFRRJ, Brazil (1993-97). In: CONGRESSO MUNDIAL DE WSAVA, 23, Buenos Aires: WSAVA-AVEACA, outubro de 1993. Anais, p. 810.

15 - ROSEKRANTZ, W.S. Discoid lupus erythematosus. In: GRIFFIN, C.E.; KWOCHKA, K.W.; MACDONALD, J.M. Current veterinary dermatology St. Louis: Mosby, 1993. p. 149-53. 
LARSSON, C. E.; OTSUKA, M. Lúpus eritematoso discóide - LED: revisão e casuística em serviço especializado da Capital de São Paulo / Discoid lupus erythematosus:

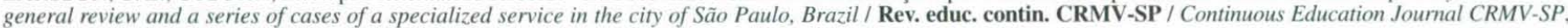
São Paulo, volume 3, fascículo 1, p. 029 - 036, 2000.

16 - SAMPAIO, S.A.P.; CASTRO, R.M.; RIVITTI, E.A. Afecções_do tecido conectivo e do subcutâneo - Lúpus eritematoso. In: Dermatologia básica, 2.ed. São Paulo: Artes Médicas, 1982. p. 177-9.

17 - SCOTT, D.W. Large animal dermatology., Philadelphia: Saunders, 1988. p. 314-7.

18 - SCOTT, D.W.; MANNING, T.O.; SMITH, C.A.; LEWIS, R.M. Linear IgA dermatoses in the dog: bullous pemphigoid, discoid lupus erythematosus and a sub corneal pustular dermatitis. Cornell vet., v. 72, n. 4, p. 394-402, 1982.

19 - SCOTT, D.W.; MILLER JÚNIOR, W.H.; GRIFFIN, C.E. Muller \& Kirk dermatologia de pequenos animais. 5.ed, Rio de Janeiro: Interlivros, 1996. p. 534-43.

20 - SCOTT, D.W.; WALTON, D.K.; MANNING, T.O.; SMITH, C.A.; LEWIS, R.M. Canine lúpus erythematosus. II - Discoid lupus erythematosus. J. Am. Anim. Hosp. Assoc., v. 19, n. 4, p. 481-8, 1983.

21 - SCOTT, D.W.; WALTON, D.K.; MANNING, T.O.; SMI-

TH, C.A.; LEWIS, R.M. Canine lupus erythematous. I -
Systemic lúpus erythematosus. J. Am. Anim. Hosp. Assoc., v. 19, n. 4, p. 461-79, 1983a.

22 - SCOTT, D.W.; WALTON, D.K.; SLATER, M.; SMITH, C.A.; LEWIS, R.M. Immune-mediated dermatosis in domestics animals: ten years after - Part I. Comp. Cont. Ed., v. 9, n. 4, p. 418-34, 1987.

23 - WHITE, S.D.; ROSYCHUK, R.A.W.; SCHUR, P.H The efficacy of tetracycline and niacinamide in the treatment of autoimmune skin disease in 20 dogs. In: ANNUAL MEMBERS MEETING AAVD \& ACVD, San Francisco, 1990. Proceedings American Academy of Veterinary Dermatology, 1990, p. 43.

24 - WHITE, S.D.; ROSYCHUK, R.A.W.; SCHUR, P.H.. Investigation of antibodies to extractable nuclear antigens in dogs. Am. J. Vet. Res., v. 53, n. 6, p. 1019-21, 1992.

25 - WILLIAMS, R.E.; MACKIE, R.M.; O'KEEFE, R.; THOMSON, W. The contribution of direct immunofluorescence to the diagnosis of lúpus erythematosus. J. Cutan. Pathol., v. 16, n. 3, p. 122-5, 1989.

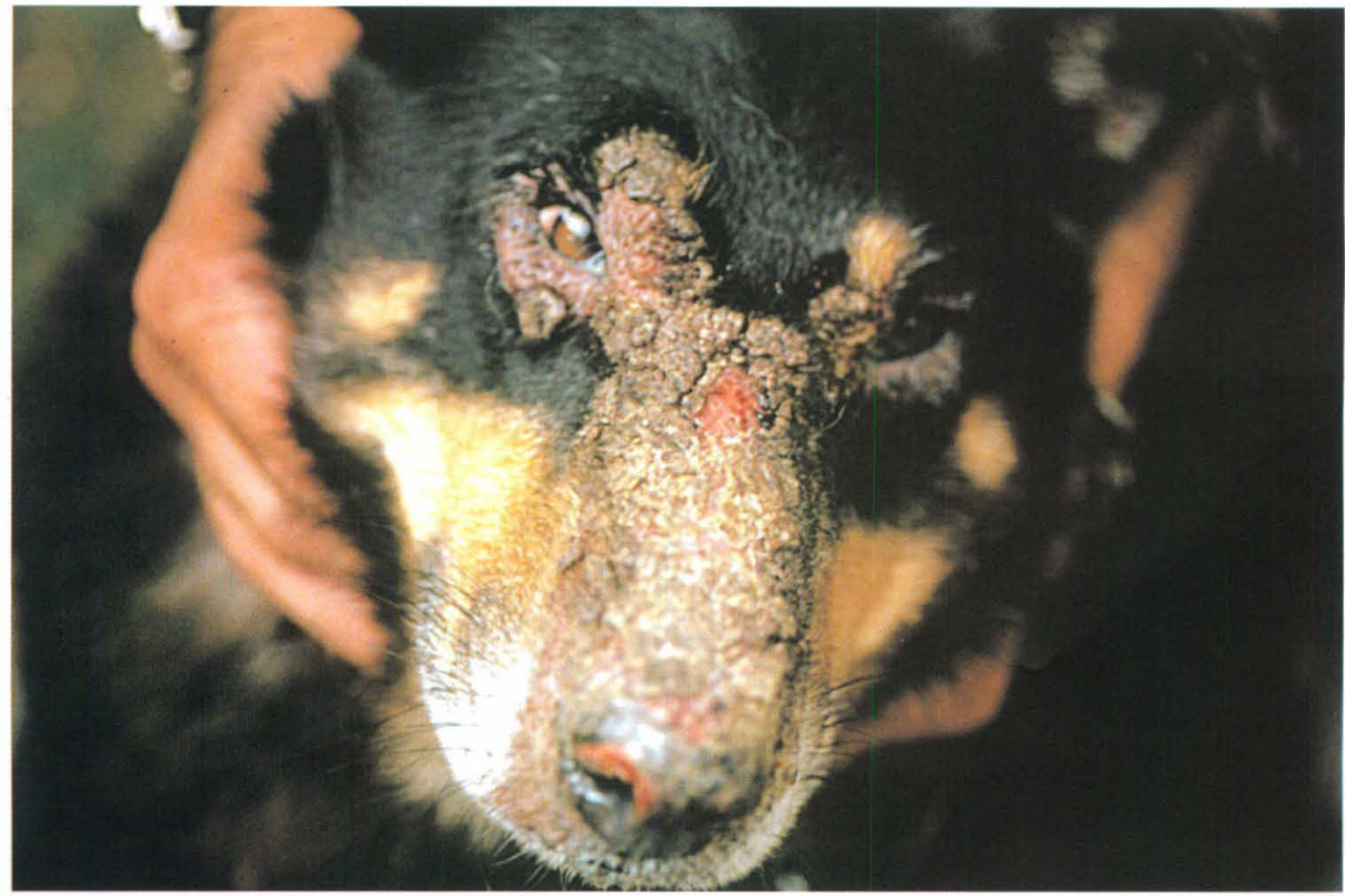

